\title{
CHEMICALLY MODIFIED ELECTRODES FOR ELECTROCATALYSIS
}

Royce H. Murray

Kenan Laboratories of Chemistry

University of Morth Carolina

Chapel Hill, North Carolina, 27514 U. S. A.

\section{ABSTP.ACT}

At a modified electrode, electrocatalysis is accomplished by an immobilized redox substance acting as an electron transfer mediator betiveen the electrode and a reaction substrate. Such mediated electrocatalysis is possible with monomolecular and multimolecular layers of the redox substance. The electron transfer mediation can assume several special forms which are identified and experimental examples are given. The differences between electrocatalytic behavior of monomolecular and multimolecular layers are discussed; electrocatalysis in the latter circumstance can include reaction rate elements of electrochemical charge and substrate migration through the multilayer in addition to the chemical rate. Theoretical ideas are presented which interconnect these three rate elements, to show that either all of the multilayer sites can participate in the electrocatalytic reaction, or only ca. a monolayer's worth, depending on the relative rates of the electrochamical charge transport, the diffusion of suhstrate, and the chemical reaction rate. 


\title{
CHEMICALLY MODIFIED ELECTRODES FOR ELECTROCATALYSIS
}

\author{
Royce W. Murray \\ Kenan Laboratories of Chemistry \\ University of Morth Carolina \\ Chapel Hill, North Carolina 27514 U. S. A.
}

Surface synthetic procedures have been developed over the past several years for inmobilizing monomolecular and multimolecular layers of electrochemically reactive substances on electrode surfaces (Murray 1980). Monomolecular layers can be chemically bonded to or chemisorbed on the electrode. An example of (monomolecular) chemical bonding is shown in Figure 1 where tetra(p-aminophenyl)porphyrin (Lennox and Murray 1978, Rockl in and Murray 1979) is amide-coupled to the carboxylic acid functions of an oxidized carbon surface, and metallated with cobalt. This modified electrode is designated $\mathrm{C} / \mathrm{Co}\left(\mathrm{NH}_{2}\right)_{4}$ TPP. Multimolecular layers of redox substances have been primarily formed from polymeric materials, which can be chemically bound (Wrighton, 1978) to the electrode or simply be applied as insoluble adherant films (Van De Mark and Miller 1978) which are permeable to supporting electrolyte ions and solvent. The redox substance can be affixed to (Itaya and Bard 1978) or be part of the polymeric matrix; examples of such redox polymers are films of polyvinylferrocene (Merz and Bard 1978) and an electropolymerized (Atruna et al 1980) form of $\left.\left[R_{1}{ }^{I} \text { (4-methy]-4'-vinyl-2,2'-bipyridine }\right)_{3}\right]\left(\mathrm{Cln}_{4}\right)_{2}$, Figure 1 . Alterna- 
tively, the redox substance can be an ionic substance (Oyama and Anson 1980a) partitioned into a polymer matrix containing fixed charged sites by ion exchange action. As an example of the latter, a film of the organosilane reagent $\left(\mathrm{C}_{2} \mathrm{H}_{5} \mathrm{O}\right)_{3} \mathrm{Si}\left(\mathrm{CH}_{2}\right)_{3} \mathrm{HH}\left(\mathrm{CH}_{2}\right)_{2} \mathrm{NH}_{2}$, en silane (Lenhard and Murray 1977, Murray 1980b), coats a superficially oxidized Pt surface, both bonding to thiat surface and forming an alkylaminesiloxane polymer film. In aqueous acid (protonating the amine sites), this anion exchanger film (Kuo 1980) strongly absorbs ferrocyanide, retaining this highly charged ion for a considerable time even when the electrode is placed in an electrolyte solution devoid of ferrocyanide. This surface will be designated $\mathrm{Pt} / \mathrm{poly}-(\underline{\text { en }} \mathrm{silane}) \mathrm{H}^{+}, \mathrm{Fe}(\mathrm{CN})_{6}^{4-}$.

The redox sites in monomolecular and multimolecular layers such as the above can be oxidized and reduced by the electrode. Trying to understand and exploit electron transfer and chemical reactions in the special circumstances of surface-confined reactants is an interesting topic (Murray 1980a). Electrochemical reactions corresponding to the

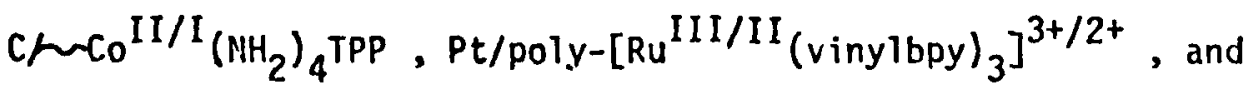
$\mathrm{Pt} / \mathrm{poly}$-(en silane) $\mathrm{H}^{+}, \mathrm{Fe}(\mathrm{CN})_{6}^{3-/ 4-}$ redox couples of these inmcbilized sites are illustrated by the cyclic voltammetric surface waves shown in Figures $2 C, 2 D, 3 A$, and $4 A$, respectively. The formal potentials of these surface vaves are near those of the analogous, unattached chemicals (Lenhard, et al 1978).

Using the electrochemical and chemical reactivities of immobilized redox substances as a means of electrocatalyzing electrode reactions of 
other substances is a particular focus of reseirch interest and, many believe, potential technological utility. Such electrocatalysis is accomplished by the imobilized substance acting as an electron transfer mediator, cycling between its reactive (CAT) and oxidized or reduced (PRECAT) states, as illustrated in the following schemes for electrocatalysis, by a monolayer

SCHEME I

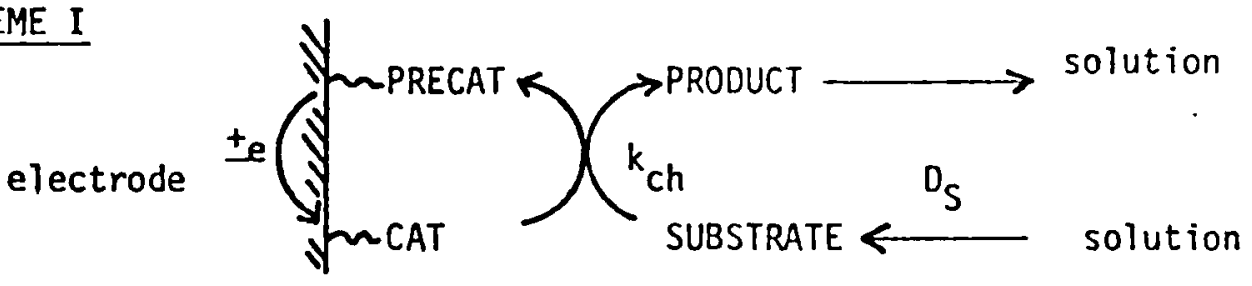

and by a multimclecular layer film

SCHEME II

Electrode

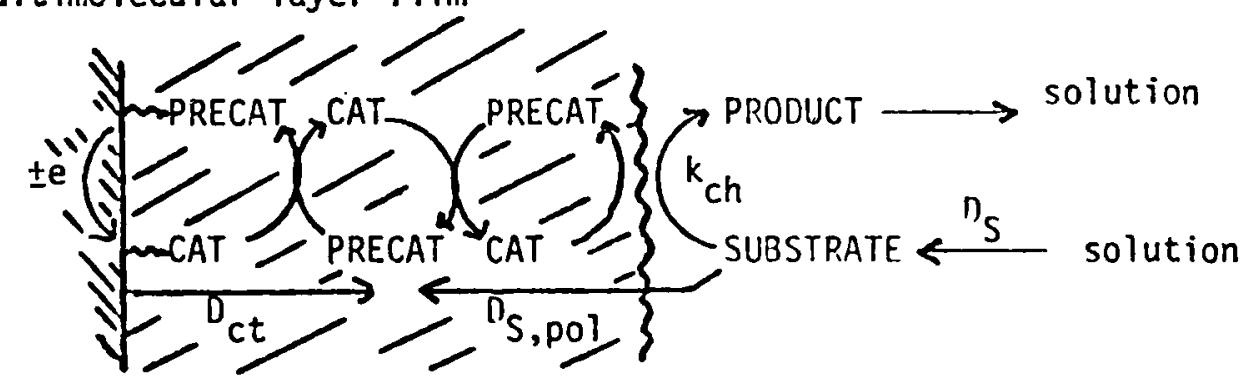

These Schenes point out two potential differences between electrocatalysis by monomolecular and multimolecular layers: (i) The quantity of mediator or catalyst sites, CAT, and by inference the electrocatalytic rate, can be much greater for multilayers, but ( $i i)$ in multilayers the electrocatalytic rate is potentially moderated by the rate at which CAT sites migrate through the polymer film $\left(D_{c t}\right)$ and the rate at which substrate SUBS diffuses through the polymer film $\left(D_{S, p o l}\right)$. Theory relating these several processes, $D_{c t}, D_{S, p o l}$, and the chenical step, $k_{c h}$, is given later in this paper. First, however, it will be useful to categorize the different special forms which molified electrode electrocatalys is 


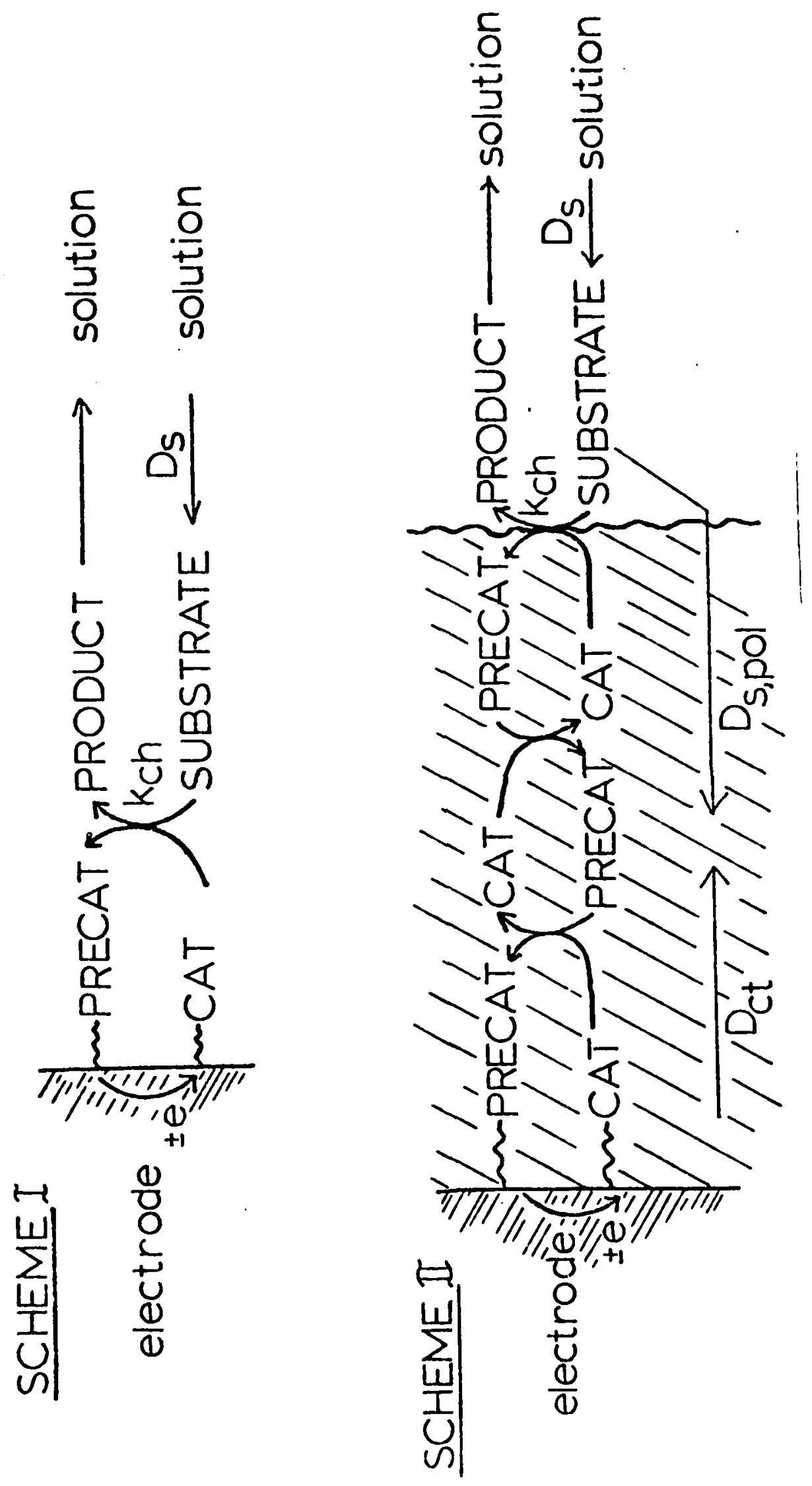


can assume. Some examples will be cited from recent experimental work at the University of Morth Carolina, full details of which are given elsewhere (Abruna, et al 1980, Leidner and Denisevich 1980, Kuo 1980, Rockl in and Murray, 1980).

\section{FORISS OF MNDIFIED ELECTRODE ELECTROCATALYSIS}

Case A. Substrate Undergoes Outer Sphere Electron Transfer At Mlaked Electrode.

Andrieux and Saveant (1978) considered theory for the case where the substrate $\underline{\text { SUBS }}$ is reduced or oxidized by a naked electrode at rates anticipated from the Marcus relations, to see if substituting mediated outer sphere electron exchange with immobilized fernstian catalyst, CAT, could enhance such rates. They concluded, not too surprisingly, that with monomolecular layers, e.g., Scheme I, such electrocatalys is was ineffectual, but that electrocatalysis with 100 molecular layers, e.g., Scheme II, could be very effective.

Case B. Substrate Reacts Slomly At Naked Electrode.

This is the most interesting situation, practically speaking. The substrate SUBS reacts slowly (sub-Marcussian rates) at naked electrode but more rapidiy (rate $k_{c h}$ ) with catalyst sites on the electrode, by either simple outer sphere or by more involved chemical pathways including transient surface adducts between CAT and SUBS. Several successes at electrocatalysis of slow substrates have been reported (Tse and Kuwana 1978, Bettelheim, et al 1980, Collman et al 1980, Oyama and Anson 1980b, Murray 1980a; Rocklin and Murray 1980), some imaginatively designing the chemical nature of catalyst sites CAT 
to yield rapid or selective reactions with the substrate. Progress in "slow substrate" electrocatalysis with modified electrodes will principally be controlled by success in designing the CAT-SUBS chemical interaction rather than by the ability to immobilize the substance CAT on the electrode surface.

Fig. 2 - "Slow substrate" electrocatalysis is illustrated in Figure 2, where SUBS $=\mathrm{PhCHBrCH}_{2} \mathrm{Br}$ is slowly reduced to styrene by a naked carbon electrode (Curve $A$ ) but on a $\mathrm{C} / \mathrm{Co}\left(\mathrm{NH}_{2}\right)_{4}$ TPP electrode is rapidly reduced (nearly diffusion controlled, Curve $B$ ), at a potential about 0.6 volt less negative than on the naked electrode and where $\mathrm{C} / \mathrm{CO}(\mathrm{C})\left(\mathrm{NH}_{2}\right)_{4}$ TPP sites are electrochemically generated on the electrode surface. This strong electrocatalysis involves less than a monolayer coverage of $\mathrm{Co}\left(\mathrm{NH}_{2}\right)_{4}$ TPP sites (Curve $\mathrm{C}$ is the cyclic voltans:ogram in the absence of $\mathrm{PhCHBrCH}_{2} \mathrm{Br}$ ). This emphasizes the difference between outer sphere-based theory (Andrieux and Saveant 1978), Case A above, and "slow substrate" electrocatalysis in Scheme I. When the cobalt porphyrin is immobilized on Pt using organosilane chemistry (Rocklin and Murray 1980), the reaction rates are similar and $k_{c h}$ could be measured as $10^{3} \mathrm{k}_{\mathrm{ch}}=10^{5} \mathrm{M}^{-1} \mathrm{sec} \cdot \cdot^{-1}$ at submonomolecular layer coverages.

Case C. Substrate Denied Acess To The Electrode.

Polymer film coatings on electrodes can restrict access or permeability of otherwise electrochemically reactive substances into 
the electrode, i.e., the product ${ }^{P D_{S, p o l}}$ is very small, $P$ being the partition coefficient of substrate from the solution into the film. In such instances, redox constituents of the film can be employed as electron transfer mediators between electrode and the excluded substance. There are three known versions of this kind of electrocatalysis.

1) Electrode/redox polymer film/solution of electroactive substance. A solution of the complex $\mathrm{Fe}^{\mathrm{II}}(\mathrm{hpy})_{2}(\mathrm{CN})_{2}$ (bpy $=2,2^{\prime}$-bipyridine) gives a diffusion controlled, reversible wave at a naked rotated disk Pt electrode for oxidation of the complex to $\mathrm{Fe}^{\mathrm{III}}(\mathrm{bpy})_{2}(\mathrm{CN})_{2}^{+}$, Figure 3 , Curve B. If the rotated disk is however first coated with a film of poly-[Ru(vinylbpy) $\left.{ }_{3}{ }^{2+}\right]$ containing $\mathrm{ca}$. $6 \times 10^{-9} \mathrm{~mol} . / \mathrm{cm} .^{2}$ of monomer sites, the normal $\mathrm{Fe}(\mathrm{bpy})_{2}(\mathrm{CN})_{2}$ oxidation wave is reduced to a few percent of its original limiting current (Curve C). The main part of the wave is shifted to a potential slightly less positive than that for oxidation of $R u^{I I}$ sites in the poly-[Ru(vinylbpy) $\left.{ }_{3}^{2+}\right] f i l m$. The $\mathrm{Fe}(\mathrm{bpy})_{2}(\mathrm{CN})_{2}$ is now being electrocatalytically being oxidized by $\mathrm{Ru}^{\mathrm{III}}$ sites located presumably near the polymer $\mathrm{film} / \mathrm{solution}$ interface. The low permeability of $\mathrm{Fe}(\mathrm{bpy})_{2}(\mathrm{CN})_{2}$ (low $\mathrm{PO}_{\mathrm{S}, \mathrm{pol}}$ ) into the poly-[Ru(vinylbpy) $\left.{ }_{3}{ }^{2+}\right]$ film is thought to be a combination of its bulkiness and the cross-linked nature of the polymer film. Positively charged substances (such as methyl viologen) are also excluded from the poly-[Ru(vinylhpy) $\left.{ }^{2+}\right]$, but anions (such as $\mathrm{Fe}(\mathrm{CN})_{6}{ }^{4-}$ ) are not.

This type of electrocatalysis can be viewed as "negative catalysis", 
since the potential for electrolysis of the substrate is shifted to higher values, rather than an overpotential being reduced. It can be a useful experimental strategy in several ways, however, such as for study of polymer film permeability $\left(\mathrm{PO}_{\mathrm{S}, \mathrm{pol}}\right)$ and for measurement of electron exchange rates $\left(k_{c h}\right)$ between one electron, nominally outer sphere redox couples, one couple being CAT in the film and the other being the excluded substrate SUSS (Oyama and Anson 1980b).

\section{2) Electrode/redox polymer film.}

During oxidation of ca. 60 monomolecular layers of $R u^{I I}$ sites in the $\left.\mathrm{Pt/poly-[Ru(vinylbpy)}{ }_{3}{ }^{2+}\right]$ film in Figure 2 , Curve $A$, it is not realistic to expect that the Pt electrode experiences direct contact with more than the innermost several layers of $\mathrm{Ru}^{\mathrm{II}}$ sites. The other, outermost sites in the film are oxidized, as schematically shown in Scheme II, by successive exchanges of electrons between neighbor poly-[Ru(vinylbpy) $\left.{ }_{3}^{2+}\right]$ and poly-[Ru(vinylbpy) $\left.{ }_{3}^{3+}\right]$ sites, the latter being generated at the electrode/polymer interface. This kind of self-electrocatalysis is probably a general mechanism for electrochemical reactions of multimolecular layer redox polymer films (Daum et al 1980, 1981, Kaufman and Engler 1979, Nowak, et al 1980). A flow of anions (and associated solvent) is necessary to provide counterions for the increasingly positively charged fixed sites, and there will be polymer lattice motions accomodating the counterion and solvent flo:s and the motions of neighbor sites toward one another, so that the overall process is 
actually somewhat complex. It is termed electrochemical charge transport. The energetics of rate control in charge transport are not yet firmly established, but its effective rate is measureable as a diffusion constant, $D_{c t} \mathrm{~cm} .{ }^{2} / \mathrm{sec}$. Denisevich (1980) for example has measured $D_{c t} \sim 4 \times 10^{-10} \mathrm{~cm} .{ }^{2} / \mathrm{sec}$. in the poly-[Ru(vinylbpy) $\left.{ }_{3}^{2+}\right]$ film.

Self-catalysis undoubtedly also plays a role in electrochemical charge transport in ion exchange polymer films containing electrostatically trapped redox ions (Oyama and Anson 1980a). We have recently measured (Kuo 1980) charge trensport rates (i.e., $D_{c t}$ ) in a $\mathrm{Pt} / \mathrm{poly}$-(en silane) $\mathrm{H}^{+}, \mathrm{Fe}(\mathrm{CN})_{6}{ }^{4-}$ film (by potential step chronoamperometry at times where the "diffusion layer" of charge transport of redox sites remained less than the film thickness (Nowak et al 1980, Daum et al 1980)). The P.t/poly-(en silane) $\mathrm{H}^{+}$film had a constant thickness $(d)$, and a succession of quantities $\Gamma_{T}\left(\mathrm{~mol} . / \mathrm{cm} .{ }^{2}\right)$ of $\mathrm{Fe}(\mathrm{CN})_{6}{ }^{4-}$ were incorporated into the film, $D_{c t}$ being measured in 7i.j. 4 each case. The results, obtained as $D_{c t}{ }^{1 / 2} \mathrm{C}$ products where $\mathrm{C}$ is the concentration of $\mathrm{Fe}(\mathrm{CN})_{C}{ }^{4-}$ sites in the film, are plotted against $\Gamma_{T}$ in Figure 4B. The plot, which has slope $D_{c t} 1 / 2 / d$, is clearly not linear at high $\mathrm{Fe}(\mathrm{CN})_{6}^{4-}$ loadings but approaches linearity at low loadings. The decrease in slope (e.g., $\left.\mathrm{D}_{\mathrm{ct}} 1 / 2 / \mathrm{d}\right)$ at high loadings may reflect electrostatic cross-linking of the film by the highly charged $\mathrm{Fe}(\mathrm{CN})_{6}^{4-}$ ions, this increased film rigidity slowing the charge transport process. At the smallest $\mathrm{Fe}(\mathrm{CN})_{6}{ }^{4-}$ loading, where 
C $2 \times 10^{-4} \mathrm{~mol} . / \mathrm{cm}^{3}$, the site-site separation of $\mathrm{Fe}(\mathrm{CN})_{6}{ }^{4-}$ units averages a very considerable 25. , yet no special decrease in $D_{c t} 1 / 2 / d$ appears. The most reasonable of several possible interpretations of the latter result is that charge transport by electron exchange between neighbor $\mathrm{Fe}(\mathrm{CN})_{6}{ }^{4-}$ and $\mathrm{Fe}(\mathrm{CN})_{6}{ }^{3-}$ sites involves significant motion of these sites toward one another prior to the actual electron hopping event.

\section{3) Electrode/redox polymer film A/redox polymer film B.}

If one redox polymer film is layered on another, a special situation occurs where the interface between the two redox polymer films is a current-rectifying barrier (Abruna, et al 1980), although no semiconductor materials or space charge effects are at work. This property is derived from the fact that, as defcribed above in Case $B(2)$, electrons are transported across redox polymer films by electron self exchange, which amounts to a narrow-band conductor with insulating gaps at other potentials. Figure 5 shows an example of a bilayer of redox polymers, in which the outer layer of poly(vinylferrocene) is isolated from the electrode by an inner layer of poly-[Ru(vinylbpy $\left.)_{3}^{2+}\right]$ so that the potential at which poly(vinylferrocene) is oxidized and re-reduced is where electron transfer-mediating $R \mathrm{U}^{\mathrm{III}}$ and $\mathrm{Ru}$ I sites are electrogenerated within the inner film, respectively, rather than at the normal ferrocene potential. Our laboratory has prepared a number of bilayer assemblies and the phenomenon appears to be a general one. Note that Figure 5 has the general appearance of a diode response, and 
indeed bilayer electrodes have promise of mimicking solid state electronic functions and even pcssibly of creating new electronic response functions.

Case D. Redox Polymer Films On Semiconductor Electrodes.

Films of redox polymers can be oxidized or reduced by absorption of light within the depletion layers of $n$ - and $p$-type semiconductor electrodes, respectively, at potentials where no electrochemical reactions of the film, or of solution substrates, should occur in the dark. This phenomenon has been employed to protect small bandgap semiconductor materials such as $n-S i^{\circ}$ from photoanodic lattice dissolution, the ferrocene containing redox polymer film.employed becoming (by favorable kinetics) oxidized instead. In order to regenerate the reduced form of the ferrocene polymer $f i l m$, substances are added to the solution which are (ideally) rapidiy oxidized by the ferricenium sites in the film. This amounts to a photocatalytic oxidation of the dissolved substance. This form of modified electrode electrocatalysis has been devioped by Wrighton and coworkers (Lewis et al, 1980, Wrighton 1979).

The above discussion shows that electrocatalysis at modified electrodes assumes diverse forms, and diverse uses probably will result. The theory for each form of electrocatalysis will differ to some extent. The theoretical discussion which follows is appropriate to Case $B$ and to Case $C(1)$. 
THEORY OF ELECTROCATALYSIS AT ROTATEO DISK ELECTRODES

When a "slow substrate" (Case B) is electrocatalytically reduced by a sub- or monomolecular layer of catalyst sites CAT on a rotated disk electrode, as in Scheme I, where the CAT sites are reversibly regenerated by reduction of FPECAT by the electrode, the limiting electrocatalytic current (Murray 1979) at the rotated disk is given by

$$
\frac{n F A}{i_{\max }}=\frac{1}{k_{c h} \Gamma C_{S}}+\frac{1}{0.62 \nu^{-1 / 6} D_{S} 2 / 3} \frac{1 / 2}{w^{1 / 2} C_{S}}
$$

where $\Gamma$ is the coverage of chemically active CAT sites $\left(\mathrm{mol} . / \mathrm{cm} .^{2}\right)$, $\mathrm{C}_{S}$ is solution substrate SUBS concentration (mo1./ $\left.\mathrm{cm}^{3}\right), D_{S}$ its diffusion constant in the solution, and $k_{c h}$ is the rate constant for the CAT-SUBS reaction according to the rate lav! $-d \Gamma / d t=k_{c h} \Gamma c_{S}$. This equation assumes, reasonably for a monomolecular layer, that substrate SUES should have relatively unrestrained permeability into the monolayer film and access to all CAT sites, i.e., $\Gamma=\Gamma_{T}$ where $\Gamma_{T}$ is the total coverage of catalyst sites in mol./ $\mathrm{cm}^{2}$ The electrocatalys is portrayed in Figure 2 is thought to correspond to this situation. With submonomolecular coverages of $\mathrm{Co}\left(\mathrm{NH}_{2}\right)_{4} \mathrm{TPP}$ immobilized on Pt (using organosilane chemistry)(Rocklin and Murray 1980), plots of equation (1) $\left(1 / i_{\max } \underline{v s} .1 / w^{1 / 2}\right)$ were linear, and $k_{c h}$ obtained from the $1 / w^{1 / 2}=0$ intercept was $10^{5} \mathrm{M}^{-1} \mathrm{sec}^{-1}$ and independent of the value of $\Gamma_{T}$. This is as yet the only quantitative kinetic data available for submonomolecular coverages in "slow substrate" electrocatalys is al though numerous qualitative reports of this type of electrocatalysis exist. 
Equation (1) contains two electrocatalytic rate elements, the rate of the chemical reaction setween $\underline{\text { CAT }}$ and SUPS, and the rate of hydrodynamic mass transport of SUBS from the solution to the catalyst surface (the right hand, Levich term). lithen the electrode is covered by multimolecular layers of catalyst sites in a polymer film, as in Scheme II, two additional rate elements can appear. These are (i) the rate at which CAT sites migrate (charge tranjport) from the electrode/polymer interface outward toward the polymer/solution interface, described by the diffusion constant $D_{c t}$, and ( $\left.i i\right)$ the product of the rate at which SUBS diffuses $\left(D_{S, p o l}\right)$ into the polymer film from the polymer/solution interface and the partition coefficient $P$ with which SUBS crosses that interface from the solution, e.g., ${ }^{P D_{S, p o l}}$, the permeability. Depending on the relative values of $k_{c h}, D_{c t}$, and $P_{S, p o l}$. these two new factors can seriously affect the overall catalytic rate as we shall show. The charge transport and substrate pemeability factors appear as modifications to the $1 / \omega^{1 / 2}$ intercept term in equation (1) (P.ock. in and Murray 1980).

An interesting property of polymeric multimolecular layer films is the possibility that electrocatalytic rates can be greatly enhanced, since the quantity of catalyst (as measured by $\Gamma_{T}$ ) can be as much as $10^{3}$ times the typical monomolecular layer value. In current studies (Oyama and Anson 1980b, Legrand and Miller 1980, Rocklin and Purray 1980) of electrocatalysis by redox polymer and by ion exchange polymer- 
trapped redox ion films, however, qualitative and quantitative rate measurements show that the electrocatalytic rate does not increase linearly with $\Gamma_{T}$ and in fact can be independent of $\Gamma_{T}$. Such results are not expected from the early theoretical analyses of modified electrode electrocatalysis (Andrieux and Saveant 1978, Anson 1980), but neither of these analyses encompassed all the rate elements pointed out above. It is possible (naum and Murray 1981, Rockl in and Murray 1980) to deal with the complexities of two additional rate elements $\mathrm{D}_{\mathrm{Ct}}$ and $\mathrm{PD}_{\mathrm{S}, \mathrm{pol}}$, and our treatment will be expanded upon here with emphasis especially on understanding how electrocatalysis can be so unresponsive to $\mathfrak{I}_{\mathrm{T}}$. The treatment, for simplicity, will be confined to the rotated disk electrode experiment, and will also assume that mass transport of SUBS from the solution is fast.

The rates of the three kinetic elements, the chemical reaction, charge transport, and substrate diffusion, are conveniently expressed as flux values (mol. $/ \mathrm{cm}^{2}{ }^{2}$ sec.) whose nominal values in the polymer film (i.e., without regard to effects of one flux on ariother) are given by the relations

$$
\begin{aligned}
& \underline{\text { (CHEM flux }}_{\text {nom }}=k_{\text {ch }} \Gamma_{T} C_{S} \\
& \underline{(c T \text { flux }}_{\text {nom }}={ }^{n_{c t} c_{c a t}} / d=D_{c t} \Gamma_{r} / d^{2} \\
& \underline{\text { SUPS flux }}_{\text {nom }}=P D_{S, p o l} C_{S} / d
\end{aligned}
$$


The actual flux values are however not independent of one another. The electrode current is controlled by $\mathrm{CT}$ flux, since that directly represents the genration of CAT sites, and at steady state, the consumption of CAT sites by the chemical reaction means that $\underline{C T}$ flux and CHEM flux must be equated. Finally, the flux of substrate inside the polymer must equal the chemical flux of SUBS consumed, which is CHEM flux. So the three actual flux values must equal one another and this means among other things that the distance intervals over which significant charge transport and substrate diffusion gradients exist may be less than the total film thickness, $\underline{d}$. The actual flux values for these are

$$
\begin{aligned}
& \underbrace{}_{\text {(CT flux })_{\text {act }}}=D_{\text {ct }} \frac{\left[C_{\left.\operatorname{cat}(x=0)^{-C} \operatorname{cat}(x=p)\right]}\right.}{p} \quad ; \text { monolayer }<p \leqslant d
\end{aligned}
$$

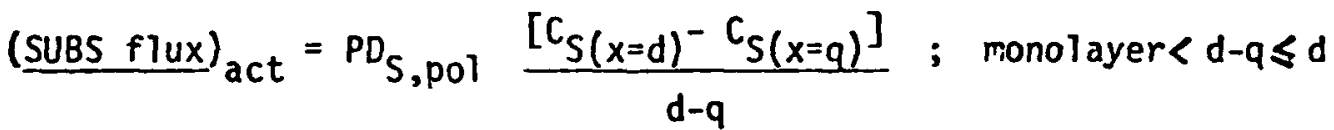

where restriction is imposed on $p$ and $d-q$ because a flux profile over less than a monomolecular layer thickness interval would not be physically sensible.

Finally, it is evident that the flux of one of the three rate elements can be sufficientiy small that it limits the flux of the others. An overall flux limited by the rate of the chemical reaction step would be expressed as

$$
\underline{(\text { CHEM fluX }})_{\text {lim }}=k_{c h} \Gamma c_{S}
$$


where $\boldsymbol{\Gamma}$ is the quantity of chemically reacting CAT sites and $\boldsymbol{\Gamma} \leqslant \boldsymbol{\Gamma}$. An overall flux limited by the rate of charge transport would be

$$
(\underline{(C T \text { flux }})_{1 \mathrm{im}}=\mathrm{D}_{\mathrm{ct}} \mathrm{C}_{\mathrm{cat}} / \mathrm{d}
$$

Flux limitation by SUBS diffusion has a special quality in that it is physically reasonahle to assume that SUBS always has access to the outermost CAT sites in the polymer film (sa. monolayer). Under this presumption, SUBS flux does not become limiting even if $\mathrm{PD}_{\mathrm{S}, \mathrm{pol}} \sim 0$.

Thus, given a set of nominal CT, CHEM, and SUBS flux values, by choice of $k_{c h}, D_{c t}$, and ${ }^{P D_{S, p o l}}$, the smaller limiting flux can be identified and the actual flux values of the others equated to it. Then using the above equations (keeping the caveat about limiting SUBS flux in mind) and calculating $p, q, C_{\text {cat }(x=p)}$, and $C_{S(x=q)}$, one can produce a set of concentration-distance profiles of CAT and SUBS within the polymer film. This has been done in Figure 6 , using a representative and realistic range of choices for $k_{c h}, D_{c t}$, and $\mathrm{PD}_{\mathrm{S}, \mathrm{pol}}$. Values of $10^{3} \mathrm{k}_{\mathrm{ch}}$ employed range from a moderately slow $10^{2} \mathrm{M}^{-1} \mathrm{sec}^{-1}$ upward to a nearly diffusion 1 imited value of $5 \times 10^{8} \mathrm{MH}^{-1} \mathrm{sec}^{-1}$ Experimental values of $D_{c t}$ are scarce, but those available fall into the range used, $10^{-11}$ to $10^{-8} \mathrm{~cm} \cdot{ }^{2} / \mathrm{sec}$. Finally, $\mathrm{PD} S$, pol data are not available at all, but the range $10^{-6}$ to $10^{-8} \mathrm{~cm} .^{2} / \mathrm{sec}$. is chosen because $P D_{S, \text { pol }}$ cannot reasonably exceed $D_{S}\left(\sim 10^{-6} \mathrm{~cm} .2 / \mathrm{sec}.\right)$ at steady state and the electrocatalytic example in Figure 2 showed that 
$\mathrm{PD}_{\mathrm{S}, \mathrm{pol}}$ could be at least $10^{2}$ smaller. $C_{\text {cat }}=1 \mathrm{M}$ is typical for a redox polymer as is $C_{S}=10^{-3}$ M for the substrate.

Figure 6 shows that choosing (CT flux) nom (SUBS flux) nom and allowing (CHEM flux) to have lesser, intermediate, and greater values (Curves $A-C$ ) has three important consequences: (i) rate control shifts from control by the chemical reaction (in Curves $A$ and $B$ ) to control by charge transport (Curve $c$ ), but ( $i i$ ) due to our (reasonable) outermost layer access assumption about SUBS, rate control does not pass to (SUBS flux), and ( $i i i)$ the gradient for SUBS extends in Curves $B$ and $C$ over a monolayer thick interval so that the quantity of C.AT sites active in the chemical reaction is only that on the outermost boundary of the film which in the limit is only a monomolecular layer value, $1-5 \times 10^{-10} \mathrm{~mol} . / \mathrm{cm} .^{2}$ In fact, Curve $B$ offers an explanation for experimental results where the electrocatalytic rate is proportional to $C_{S}$ (a criterion for chemical rate control) but not proportional to or independent of $\Gamma_{T}$, as in the experimental results cited above. Rocklin and Murray (1980) proposed the conditions of Curve $B$ as an explanation for electrocatalytic results on imnobilized $\mathrm{CO}\left(\mathrm{NH}_{2}\right)_{4} \mathrm{TPP}$ and $\mathrm{PhCHBrCH}_{2} \mathrm{Br}$ substrate. Profiles such as those in Curves A-C may well prove to be common once further experimental studies are completed.

A different representation of thr profiles of Curves $A-C$, Figure 6 , fig is given in Figure 7. This portrays more directly the limiting flux 
values obtained over a range of $k_{c h}$ for the situation where. (CT flux $)_{\text {nom }}>$ (SUBS flux $_{\text {nom }}$. The conditions of Curves $A-C$, Figure 6, are the heavy dots on this figure. At low chemical reaction rates, the advantages of large $\boldsymbol{\Gamma}_{\mathrm{T}}$ are retained (e.g., faster chemical rate), but once the chemical reaction and substrate diffusion fluxes become similar (at larger $k_{c h}$ ), this advantage is lost (the profile becomes that in Curve B, Figure 6), and the thicker redox polymer film exerts no greater electrocatalytic rate than would a monomolecular layer. The thicker polymer film also enters the regime of charge transport rate control (Curve C, Figure 6) at a lower chemical rate $k_{c h}$ than with the thinner polymer film, owing to the proportionality of $d$ to $\Gamma_{T}$. These results assert, then, that for the "slow substrate" kind of electrocatalytic reaction, a very thin film of CAT sites can yield the faster electrocatalytic conversions when the chemical rate constant $k_{c h}$ is large. This is the opposite of the prediction by Andrieux and Saveant (1978) who did not consider the important charge transport rate element.

In Curves D-F, Figure 6, an analogous set of profile calculations has been done for the condition that SUBS flux $>$ CT flux . Curve D is identical to Curve $A$; again for slow chemical rates, the reactive CAT sites correspond to $\Gamma_{T}$. Curve $E$ is a more complex situation in which it is difficult to quantitatively formulate the number of active CAT sites but they are less than $\Gamma_{T}$. Curve $F$ is analogous to Curve $C$ in that the CAT-SIJBS reaction zone collapses to a monolayer-like thickness 
of CAT sites hut this thickness interval now occurs in the depths of the polymer film. The CAT and SUIBS fluxes are co-limiting in this instance.

Finally, to summarize the lessons learned from the above computations relevant to designing redox polymer film catalysts: (i) when the chemical reaction rate constant is small, the catalyst film can profitably be large, since most or all CAT sites will participate in the reaction., ( $i i)$ when the chemical reaction rate constant is large but not as large as one wishes it to be, then the catalyst film should be as thin as practical so as to increase CT flux, and probably the film should not be highly cross-linked since this may decrease SUBS flux . A.t first glance the latter properties would seem to be antagonsitic to a goal of stable polymer films. Important practical limitations and constraints on some kinds of electrocatalytic chemistry and films will surely arise from stability requirements of operating electrocatalysis, of course. The extent of these is not evident yet and it remains for continued development of electrocatalytic reactions for this to become satisfactorily appreciated.

\section{ACKNOHLEDGEMENT}

The author acknowledges with gratitude hospitality of Stanford University during the writing of this paper as a Guggenh $m$ Fellow, and the imaginative efforts of his colleagues at the University of North C rolina, Mr. R. D. Rocklin, Mr. K. Kuo, R. R. Leidner, and Dr. P. Denisevich, from shose work the electrocatalytic illustrations of 
Figures 2-5 were drawn. The research was supported by grants from the Nlational Science Foundation and the Office of Naval Research.

\section{FIGURE LEGENDS}

Figure 1. Exemplary electrocatalytic layers on chemically modified electrodes.

Figure 2. Electrocatalysis of $\mathrm{PhCHBrCH}_{2} \mathrm{Br}$ by a $5 \times 10^{-11} \mathrm{~mol} . / \mathrm{cm} .^{2}$ $\mathrm{C} / \sim \mathrm{Co}\left(\mathrm{NH}_{2}\right)_{4} \mathrm{TPP}$ surface in $0.1 \mathrm{M} \mathrm{Et} \mathrm{NClO}_{4} / \mathrm{OHSO}$.

Figure 3. Cyclic voltammetry of $\mathrm{Pt} / \mathrm{poly}-\left[\mathrm{Ru}\left(\mathrm{v}\right.\right.$ inylbpy) $\left.{ }_{3}{ }^{2+}\right]$ electrode (Curve A), $1 \mathrm{mM}$ Fe(bpy $)_{2}(\mathrm{CM})_{2}$ at naked $\mathrm{Pt}$ rotated disk (Curve $\mathrm{B}$ ) and at $\mathrm{Pt} / \mathrm{poly}-\left[\mathrm{Ru}\right.$ (vinylbpy) $\left.{ }_{3}{ }^{2+}\right]$ rotated disk (Curve $\mathrm{C}$ ) all in $0.1 \mathrm{M} \mathrm{Et}_{4} \mathrm{NClO}_{4} / \mathrm{CH}_{3} \mathrm{CN}$.

Figure 4. Curve $\mathrm{A}$, cyclic voltanmetry of $\mathrm{Fe}(\mathrm{CN})_{6}{ }^{4-}$ electrostatically trapped in a $\mathrm{Pt} / \mathrm{poly}$-(en silane) $\mathrm{H}^{+}$film, $0.5 \mathrm{M} \mathrm{KCl}, \mathrm{pH} 3.2$ (glycine). Curve $B$, charge transport rate through ca. $1600 \AA$ $\mathrm{Pt} / \mathrm{poly}$-(en silane) $\mathrm{H}^{+}, \mathrm{Fe}(\mathrm{CN})_{6}^{4-}$ film containing various amounts of trapped $\mathrm{Fe}(\mathrm{CN})_{6}^{4-}$. $\mathrm{D}_{\mathrm{ct}}=2-7 \times 10^{-9} \mathrm{~cm}^{2} / \mathrm{sec}$.

Figure 5. Niode like cyclic voltanmogram of redox polymer bilayer $\mathrm{Pt} /$ poly-[Ru(vinylbpy) $\left.{ }_{3}{ }^{2+}\right] / \mathrm{PVFer}$ in $0.1 \mathrm{M} \mathrm{Et}_{4} \mathrm{NClO}_{4} / \mathrm{CH}_{3}$ r.N.

Figure 6. Estimated CAT $(\cdots)$ and diffusing substrate SIIPS $(-)$ concentration-distance profiles within polymer film on electrode, assuming fast supply of SIISS from solution to film surface, for indicated orderings of nominal CT flux, CHEM flux, and SIJBS flux, and $\Gamma_{T}=2 \times 10^{-9} \mathrm{~mol} .1 \mathrm{~cm}^{2}, d=2 \times 10^{-6} \mathrm{~cm}$. , and $C_{\text {cat }}=1 \mathrm{M}$; 
(Curves $A-C$ ) $P_{S, P O 1}=2 \times 10^{-8} \mathrm{~cm}^{2} / \mathrm{sec}$., (Curves $D-F$ ) $P_{S, P 01}=$ $1 \times 10^{-6} \mathrm{~cm}^{2} / \mathrm{sec}$., (Curves $\left.A-C\right) D_{c t}=2 \times 10^{-9} \mathrm{~cm}^{2} / \mathrm{sec}$., (Curves $D-F$ ) $D_{c t}=1 \times 10^{-11} \mathrm{~cm} .{ }^{2} / \mathrm{sec}$; $10^{3} \mathrm{k}_{\mathrm{ch}}=10^{2}$ (Curves $A, D$ ), $10^{6}$ (Curve B), $10^{8}$ (Curve C), $5 \times 10^{4}$ (Curve E), $5 \times 10^{8}$ (Curve F) $\mathrm{M}^{-1} \mathrm{sec}^{-1}$

Actual fluxes limited by boxed [flux] are $2 \times 10^{-10}, 10^{-7}, 10^{-6}$, $2 \times 10^{-10}, 5 \times 10^{-9}, 5 \times 10^{-7} \mathrm{~mol} . / \mathrm{cm}^{2}$ sec., for Curves $A-F$, respectively.

Figure 7. Estimated limiting electrocatalysis flux for redox polymer with $\Gamma_{T}=1 \times 10^{-10}(-\infty-\infty), 2 \times 10^{-9}(-)$, and $2 \times 10^{-8}(--) \mathrm{mol} . / \mathrm{cm}^{2}$ versus chemical rate $10^{3} \mathrm{k}_{\mathrm{ch}}, \mathrm{H}^{-1} \mathrm{sec} .^{-1}$ Heavy dots represent conditions of Figure 6 Curves $A-C$. Arrows represent approximate maximum and minimum electrocatalytic fluxes practically measureable with rotated disk electrode. Light lines are nominal flux. 


\section{REFERENCES}

1. Abruña, H. D., Denisevich, P., Umaña, M., Meyer, T. J., Murray, R. H., 1980 J. Amer Chem. Soc. 102,0000

2. Andrieux, C. P., Saveant, J. M., 1978, J. Electroanal. Chem. 93163

3. Anson, F. C., 1980 J. Phys. Chem, 840000

4. Bettelheim, A., Chan, R. J. H., Kuwana, T.. 1980 J. Electroanal. Chem. 11093

5. Colliman, J. P., et al 1980 J. Amer Chem. Soc. 1026027

6. Daurn, P., Lenhard, J. R., Rolison, D. R., Murray, R. W. 1980 J. Amer. Chen. Soc. 1024649

7. Daum, P., Murray, R.H., 1981 J. Phys. Chem. 850000

8. Degrand, C., Miller, L. L., 1980 J. Amer. Chem. Soc. 1025728

9. Denisevich, P., 1980, Univ. No. Car., unpublished results

10. Itaya, K., Bard, A. J., 1978 Anal. Chem. 501487

11. Kaufman, F. B., Engler, E. M., 1979 J. Amer. Chem. Soc. 101547

12. Kuo, K., 1980, Univ. No. Car., unpublished results

13. Leidner, R., Denisevich, P., 1980, Univ. No. Car., unpublished results

14. Lenhard, J. R., Murray, R. H., 1977 J. Electroanal. Chem. 78195

15. Lenhard, J. R., et al 1978 J. Amer. Chem. Soc. 1005213

16. Lennox, J. C., Murray, R. H., 1978 J. Amer. Chem. Soc. 1003710

17. Lewis, N., Bocarsly, A. B., Wrighton, M. S., 1980 J. Phys.

Chem. 842033

18. Merz, A., Eard, A. J., 1978 J. Amer. Chem. Soc. 1003222

19. Murray, R. W., 1979, Univ. ilo. Car., unpublished results 
20 a) Hurray, R. H., 1980 Accts. Chem. Res. 13135

b) Murray, R. H., 1980 Silylated Surfaces (125-137), Leyden, D. E., Collins, W. T. (eds.) Gordon and Breach

21. Howak, R. J., et al 1980 Ana1. Chem. 52315

22. a) Oyama, N, Anson, F. C., 1980 J. Electrochem. Soc. 127 247, 249

b) Oyama, N., Anson, F. C., 1980 Anal. Chem. 521192

23. Rocklin, R. D., Murray, R. H., 1979 J. Electroanal. Chem. IC0 271

24. Rocklin, R. D., Murray R. H., 1980, to be submitted for publ ication

25. Tse, D. C. S., Kusvana, T., 1978 Ana1. Chem. 501315

26. Van De Mark, H. R., Miller, L. L., 1978 J. Amer. Chem. Soc. 1003223

27. Wrighton, M. S., et al 1978 J, Electroanal. Chem. 87429

28. Hrighton, M. S., 1979 Accts. Chen. Res. 12303 

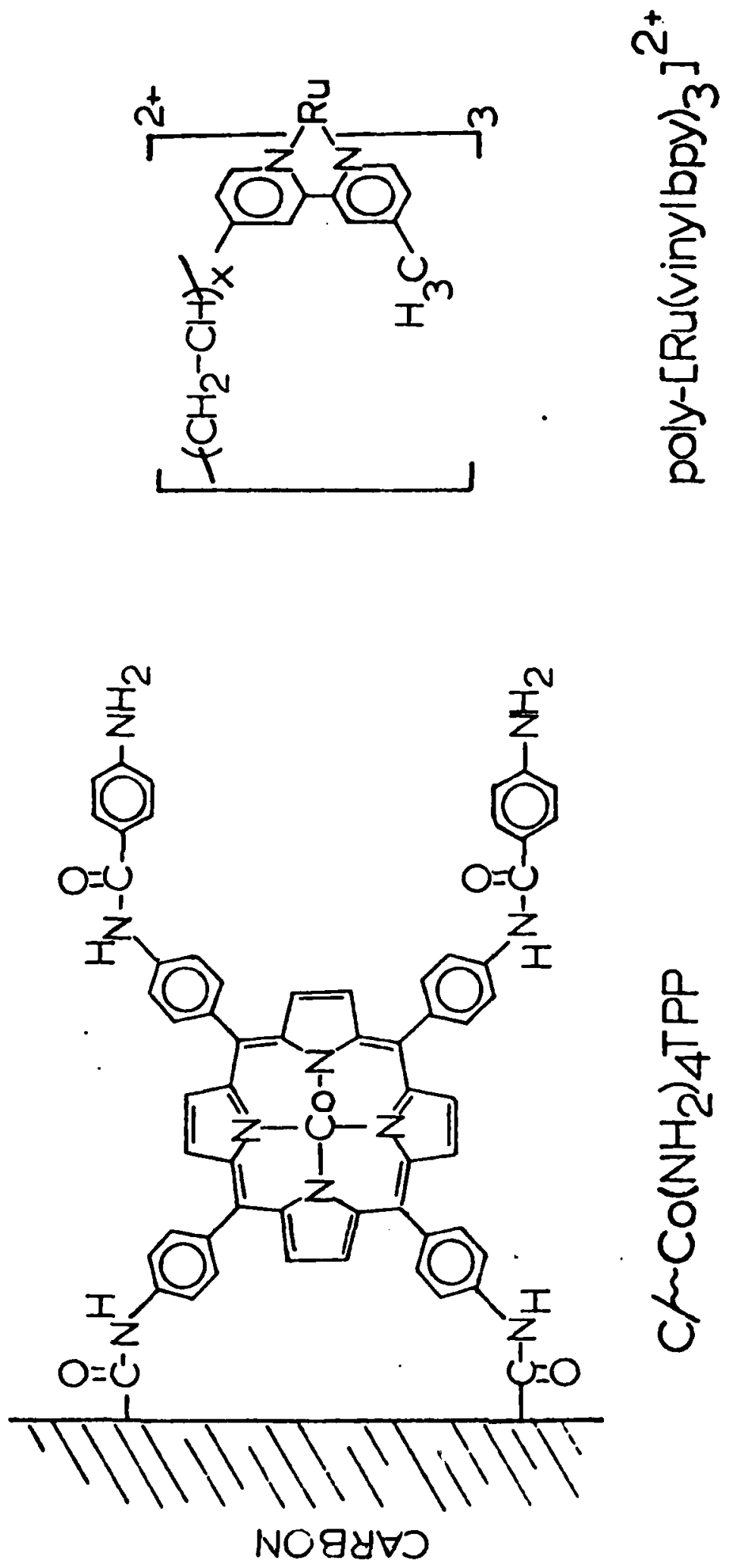


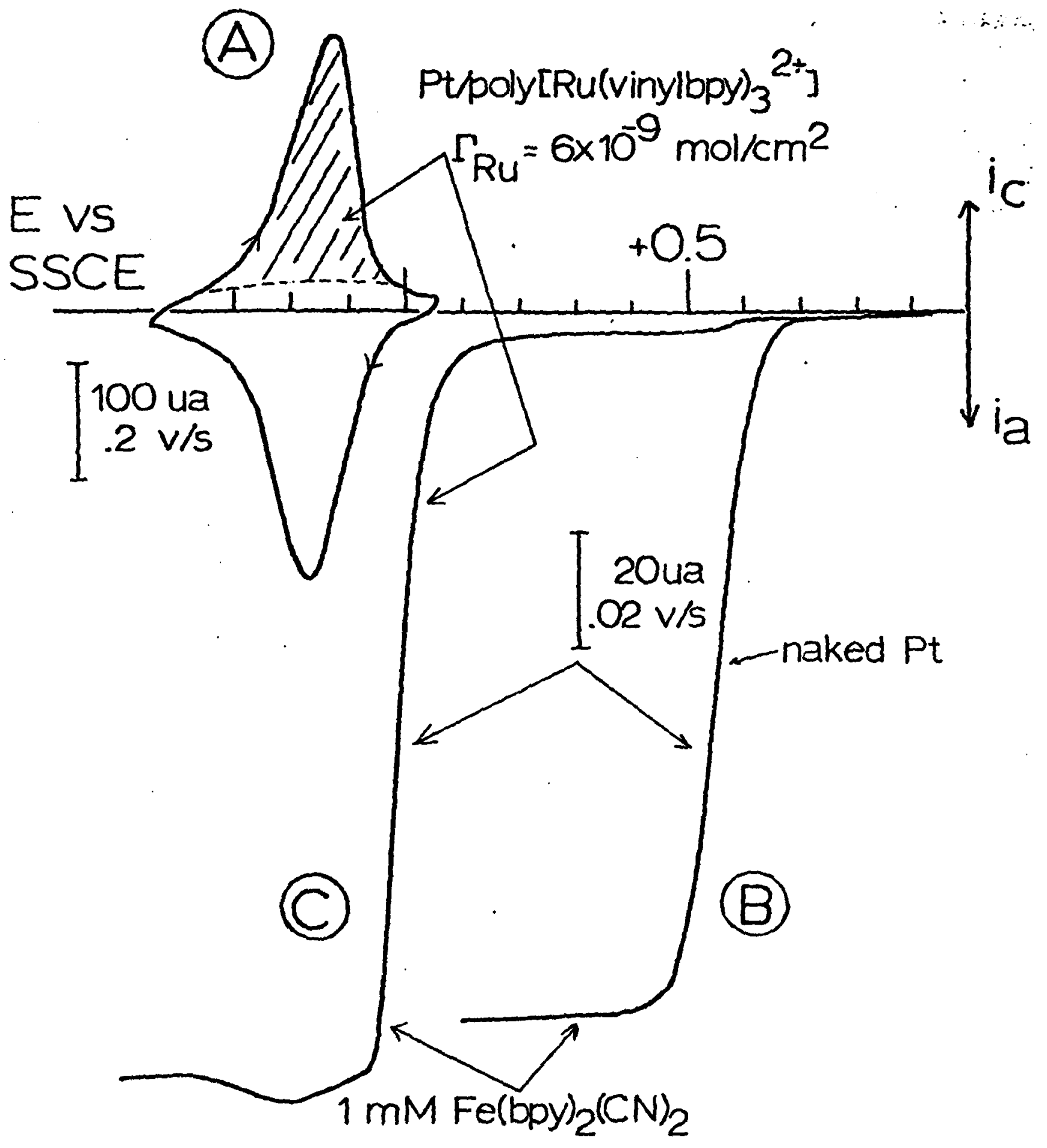




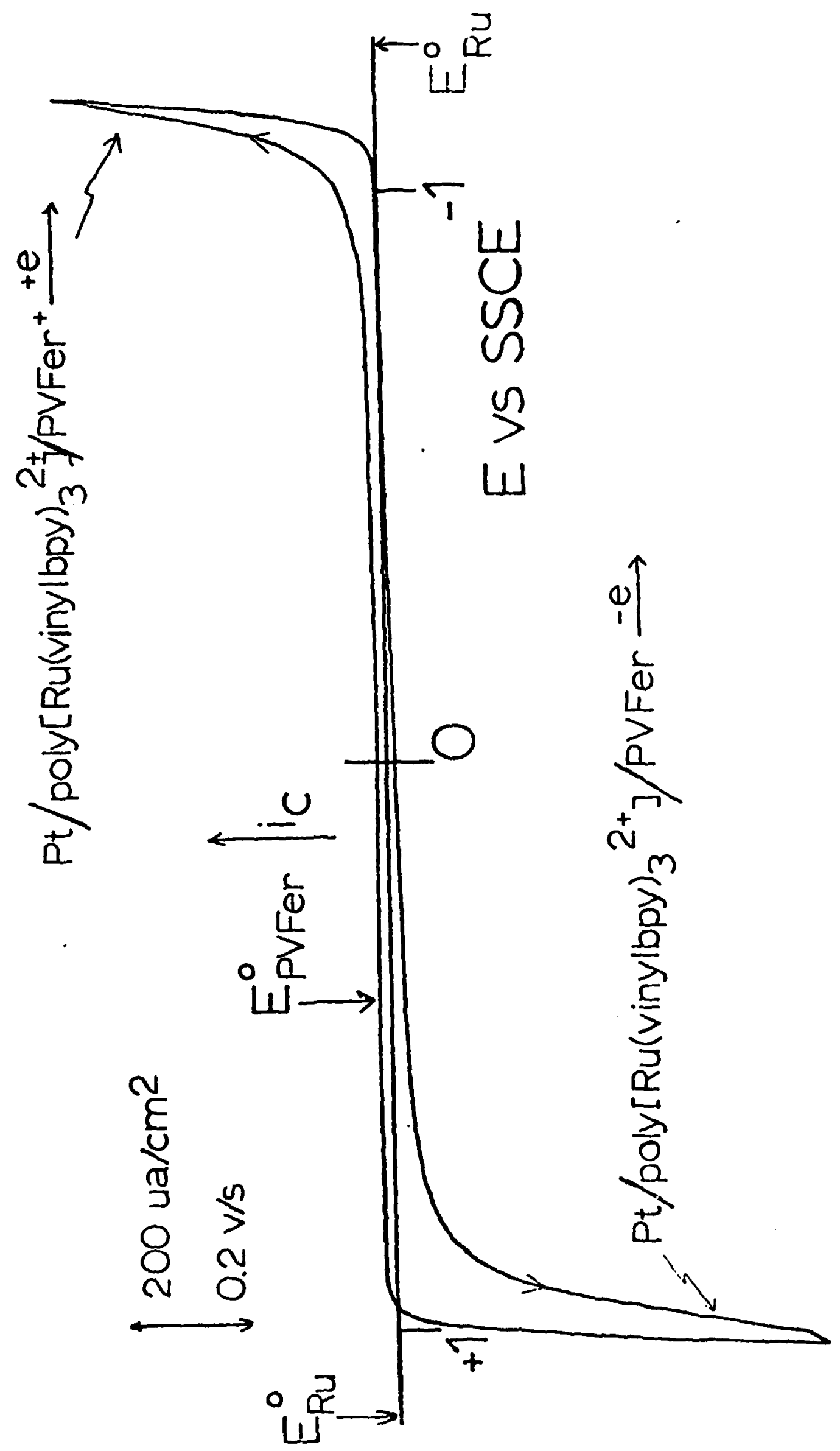




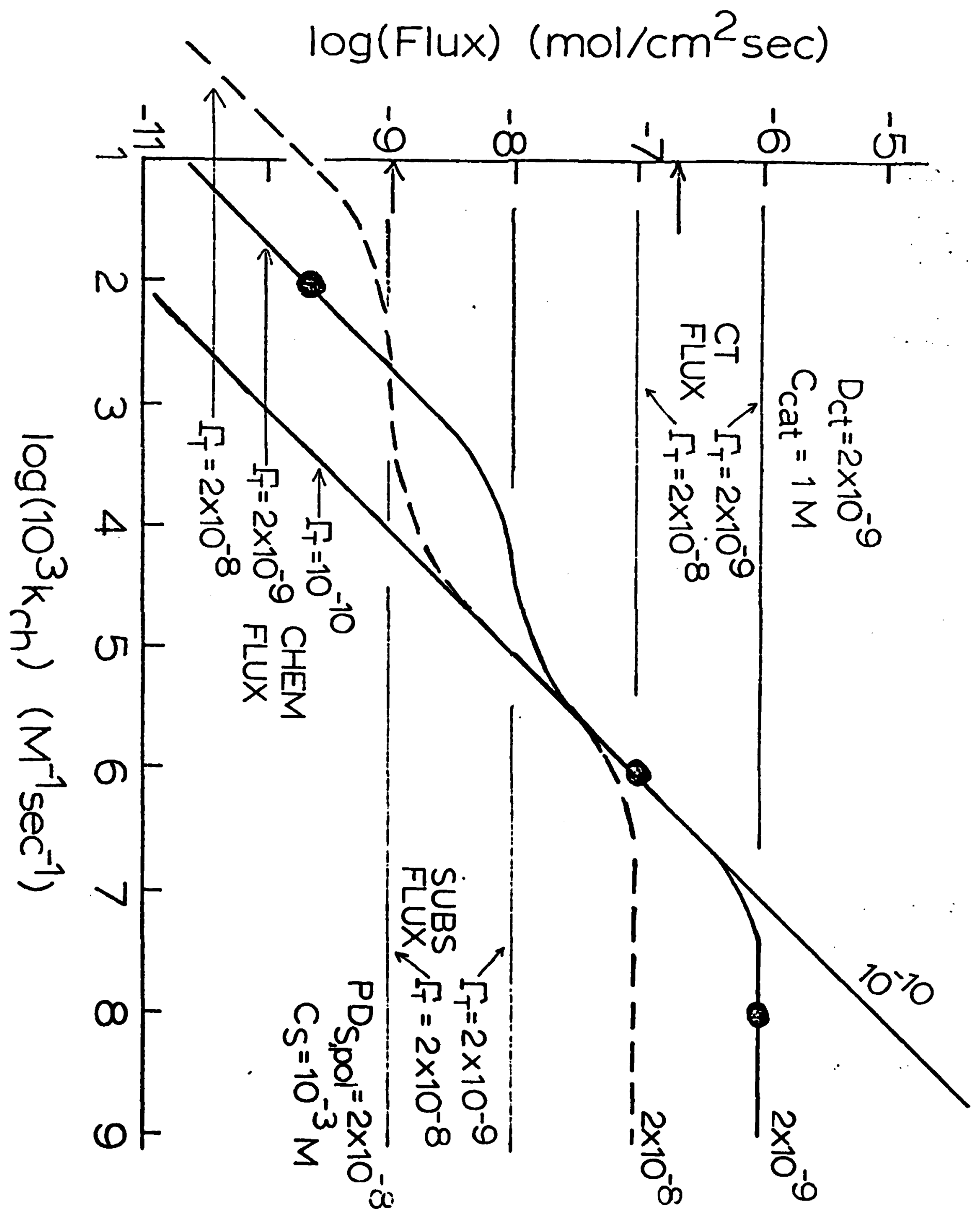


$\log \left(\right.$ conc. $\begin{array}{l}\text { catalyst sites } \ldots, M) \\ \text { substrate }\end{array}$
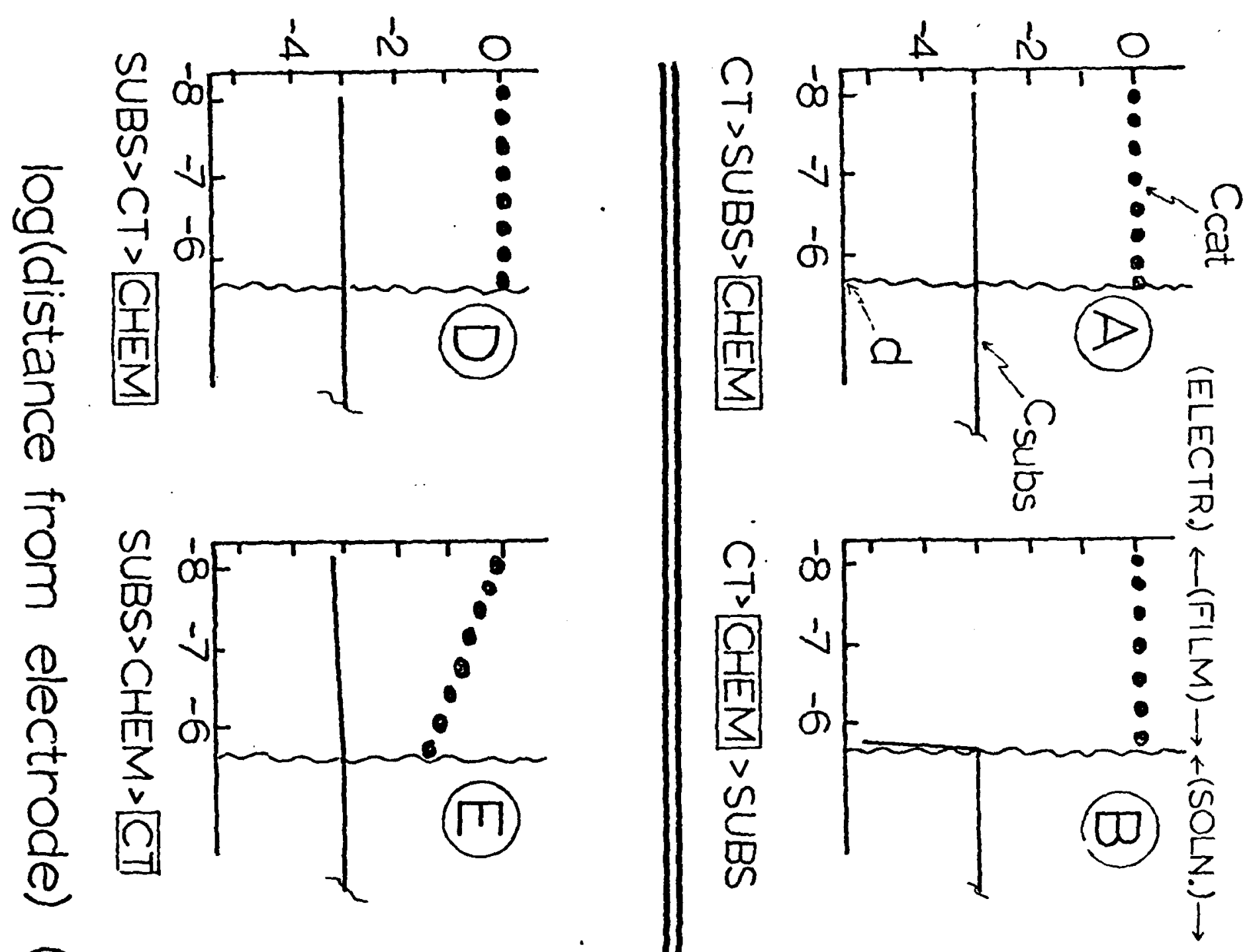

$\widehat{3}$
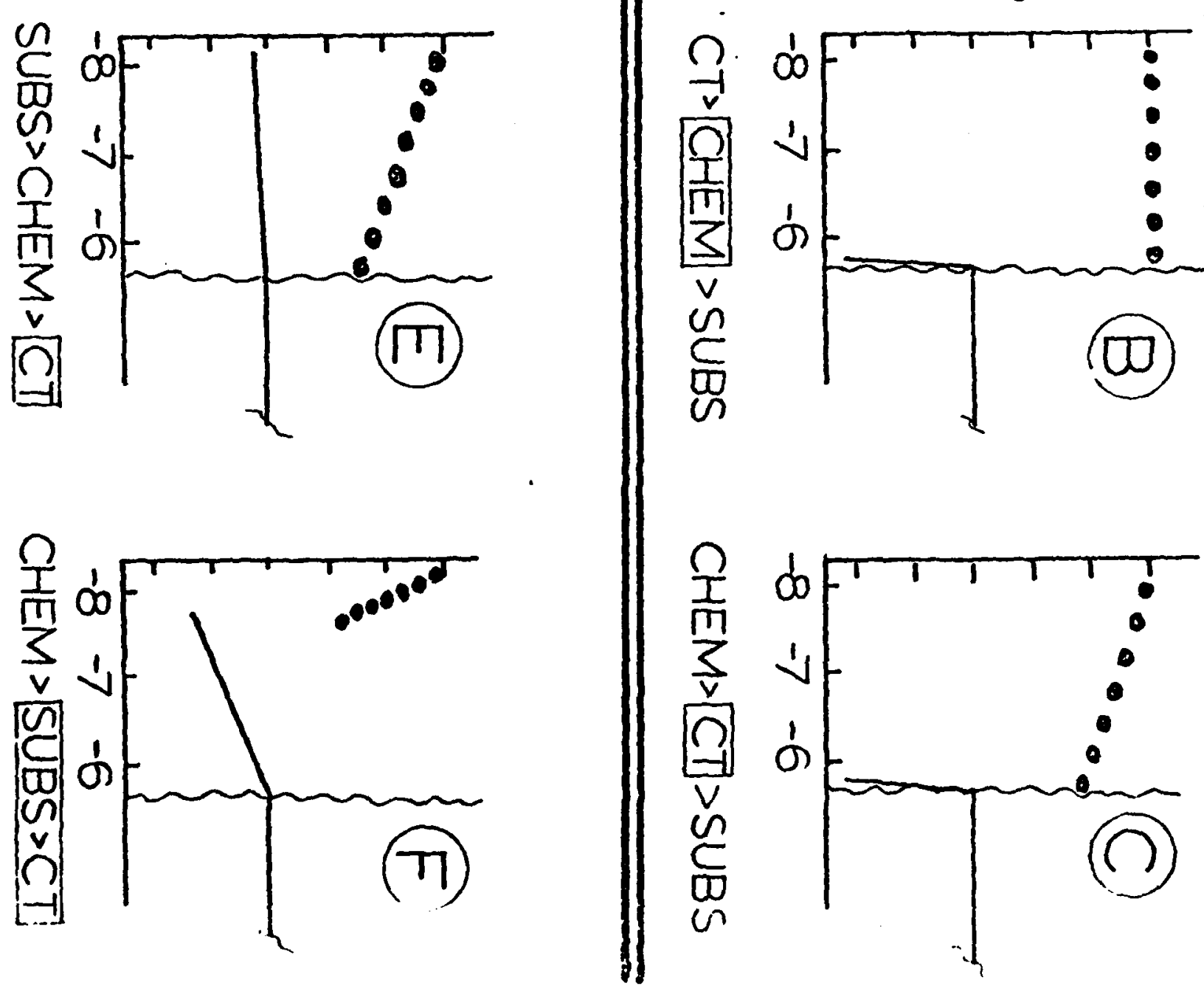


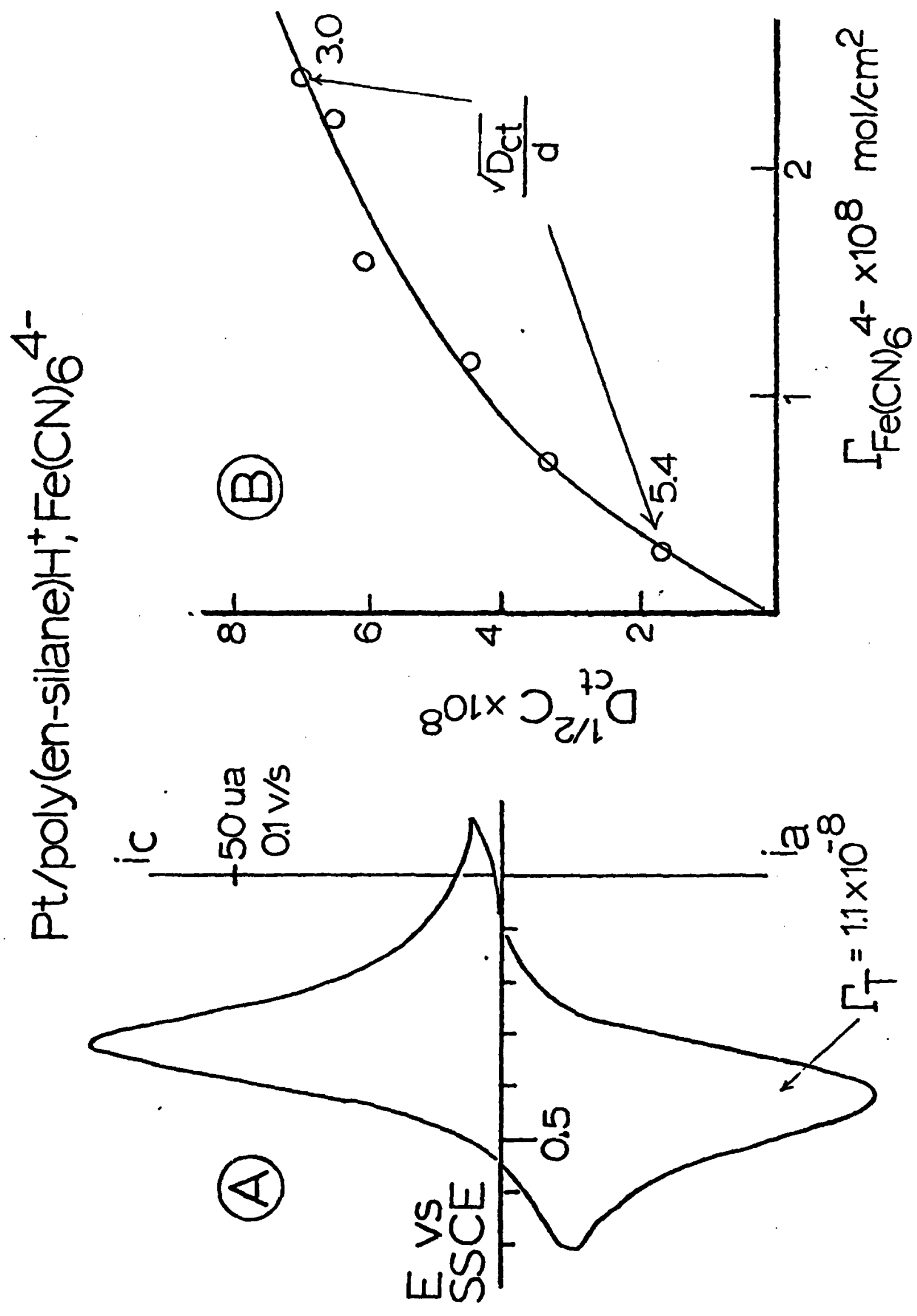




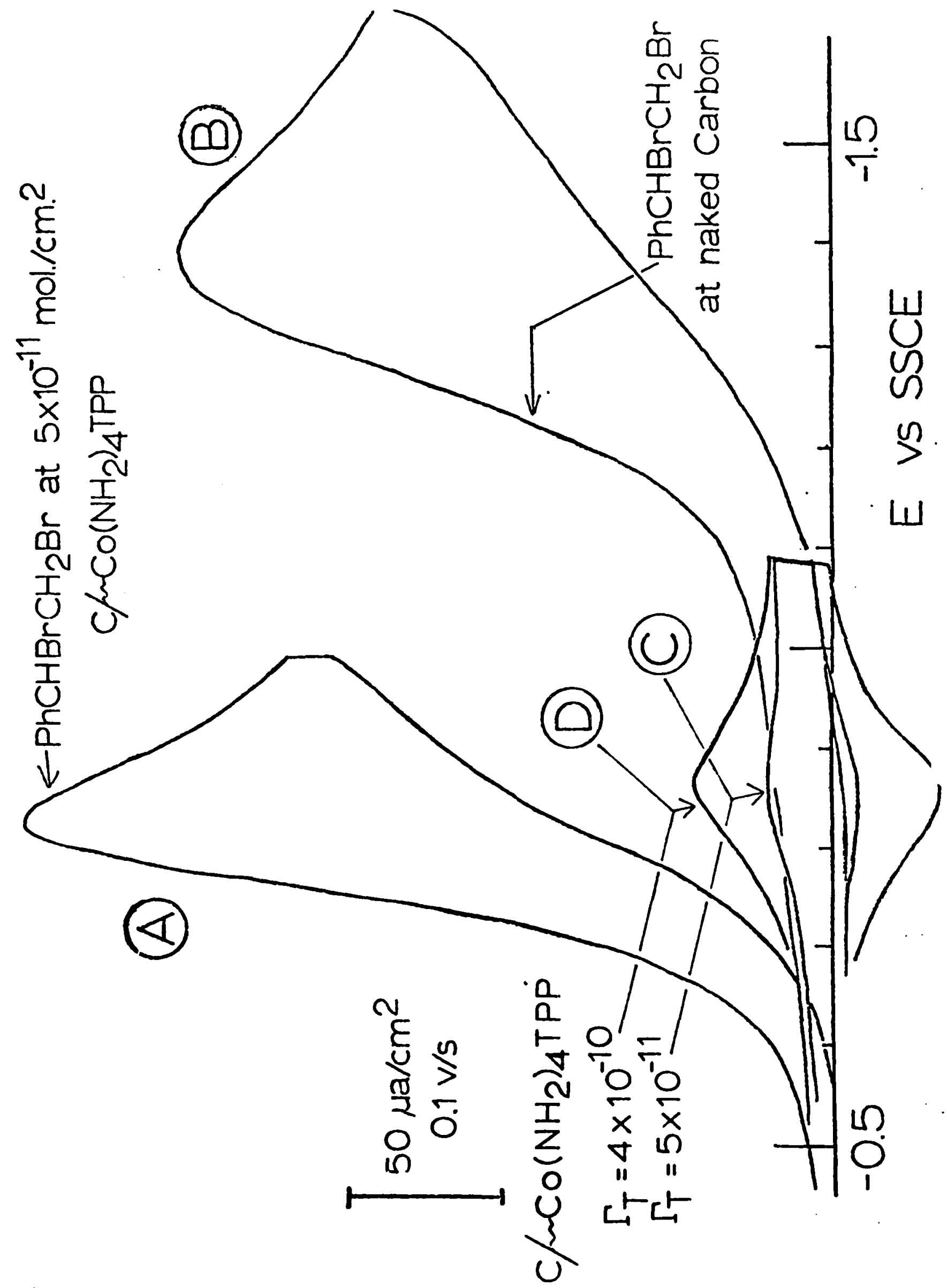

